\title{
O Plano de Ações Articuladas e o regime de colaboração: promessas não cumpridas de fortalecimento das relações de colaboração entre os municípios e a união
}

\author{
The Plan of Articulated Actions and the collaboration regime: unfulfilled \\ promises of fortifying the relations of collaboration between the counties and \\ the federal union
}

El Plan de Acciones Articuladas y el régimen de colaboración: promesas no cumplidas para fortalecer las relaciones de colaboración entre los municipios y

la unión

\section{LUÍS GUSTAVO ALEXANDRE DA SILVA}

Resumo: $\mathrm{O}$ artigo analisa as limitações do Plano de Ações Articuladas (PAR) no cumprimento do propósito de fortalecer as relações de colaboração entre os municípios e a união. A pesquisa utiliza como metodologia a aplicação de questionários e a realização de entrevistas semiestruturadas. Os resultados mostram os limites dessa proposição em razão do grau de precariedade dos sistemas municipais de educação e da perspectiva de planejamento submetida aos princípios da descentralização e dos parâmetros da nova gestão pública.

Palavras-chave: Gestão de Sistemas Municipais de Educação; Regime de Colaboração.

Abstract: This article analyses the limitations of the Plan of Articulated Actions (PAR) in accomplishing its aims on fortifying the relations of collaboration between the counties and the federal union. The methodology used in the research were questionnaires and half-structured interviews. The results show the limits of its proposal, due to precariousness of municipal education systems, to the planning view, subordinated to decentration principles, and to the new public management parameters.

Keywords: Management of Municipal Education Systems; System of collaboration.

Resumen: Este artículo analiza las limitaciones del Plan de Acciones Articuladas (PAR) en el cumplimiento del propósito de fortalecer las relaciones de colaboración entre los municipios y la unión. La investigación utiliza como metodología la aplicación de cuestionarios y la realización de entrevistas semiestructuradas. Los resultados muestran los límites de esta proposición, 
debido al grado de precariedad de los sistemas municipales de educación y la perspectiva de planificación sometida a los principios de la descentralización y de los parámetros de la nueva gestión pública.

Palabras clave: Gestión de Sistemas Educativos Municipales; Régimen de colaboración.enseñanza híbrida; hibridación de la enseñanza.

\section{INTRODUÇÃO}

O presente estudo refere-se aos resultados alcançados pela pesquisa "Organização e gestão dos sistemas municipais de educação em Goiás”, que tem como objetivo analisar os impactos das atuais políticas públicas educacionais, em especial, do Plano de Desenvolvimento da Educação (PDE) e do Plano de Ações Articuladas (PAR) na organização e gestão dos sistemas municipais de educação no Estado de Goiás.

A constituição da amostra da pesquisa se deu, inicialmente, pela definição dos elementos conceituais e institucionais que caracterizam um sistema municipal de educação. Segundo a literatura da área, o processo de institucionalização do sistema municipal de educação desenvolve-se com a formulação de um conjunto de leis e decretos capazes de regulamentar e definir sua estrutura, dentre eles, a lei municipal de criação do sistema municipal de educação, a lei municipal de criação do conselho municipal de educação, a portaria de criação do comitê local do compromisso, a lei de criação do Conselho do Fundo de Manutenção e Desenvolvimento da Educação Básica (Fundeb) e a lei de criação do plano de cargos e salários para os profissionais da educação (BORDIGNON, 2009; ROMÃO, 2010).

Para definir com maior precisão os municípios e os respectivos sistemas municipais de educação que fariam parte da pesquisa, adotaram-se os seguintes critérios:

a) municípios com menos de 20.000 habitantes a partir dos dados disponibilizados pela Fundação Instituto Brasileiro de Geografia e Estatística $\mathrm{IBGE}^{2}$;

b) municípios que institucionalizaram seus sistemas municipais de educação, ou seja, possuem legislação que regulamenta a criação e a existência do

\footnotetext{
1 Esta pesquisa é financiada pelo CNPq no âmbito da Chamada Pública MCTI/CNPq nº 14/2013 Universal.

2 Os municípios com menos de 20.000 habitantes correspondem, aproximadamente, a $80 \%$ dos municípios goianos (BRASIL, 2017a).
} 
sistema municipal de educação, do conselho municipal de educação, do comitê local do compromisso, do conselho do Fundeb e do plano de cargos e salários para os profissionais da educação;

c) $22 \%$ dos municípios goianos com menos de 20.000 habitantes e que institucionalizaram seus sistemas municipais de educação;

d) $11 \%$ dos municípios com as menores notas IDEB 2011 e 11\% dos municípios com as maiores;

e) definição dos municípios participantes por sorteio.

Com base nos critérios definidos para definição da amostra, foram escolhidos os seguintes municípios no Estado de Goiás: Israelândia, Itaguari, Ouro Verde, Morro Agudo de Goiás, Palmelo, Rubiataba, Aparecida do Rio Doce, Flores de Goiás, Panamá, Vicentinópolis, Turvelândia e Goianápolis.

A pesquisa utilizou como metodologia de coleta de dados a aplicação de questionários e a realização de entrevistas semiestruturadas com os secretários municipais de educação. Após a análise documental, foram elaborados questionários e entrevistas a partir de áreas específicas de investigação, provenientes das dimensões definidas pelo PAR: perfil do dirigente municipal de educação (DME) e dados educacionais do município; gestão educacional; condições de profissionalização dos trabalhadores em educação; infraestrutura física e recursos pedagógicos.

A realização da pesquisa possibilitou a verificação da estrutura educacional existente nos sistemas municipais de educação e das contradições relativas ao processo de implementação do Plano de Ações Articuladas. Diante desse contexto foram levantados questionamentos sobre as reais possibilidades de o PAR cumprir seus objetivos de fortalecer as relações de colaboração entre os entes federados (município e união), diante do grau de precariedade estrutural dos sistemas municipais de educação e da perspectiva de planejamento contida no instrumento PAR.

\section{O PAR E AS CONTRADIÇÕES CONCERNENTES À EFETIVAÇÃO DO REGIME DE COLABORAÇÃO}

O planejamento educacional tem ganhado, nos últimos anos, significativo destaque como política pública. Essa perspectiva pode ser observada com a aprovação do Plano de Desenvolvimento da Educação (PDE), do Plano de Ações Articuladas (PAR) e do Plano Nacional de Educação (PNE 2014-2024). Na óptica do governo federal, esse conjunto de políticas públicas tem por finalidade planejar a educação e propor o alcance de objetivos relativos à elevação da oferta e da qualidade da Educação Básica, a serem atingidos em médio e longo prazo. 
Dentre as ações relativas ao planejamento educacional implantadas no governo Lula (2003-2010), destacam-se o Plano de Desenvolvimento da Educação (PDE) e o Plano de Ações Articuladas (PAR), uma vez que introduzem novo paradigma de planejamento para os sistemas públicos de educação. O PDE foi lançado simultaneamente à promulgação do Decreto no 6.094, de 24 de Abril de 2007, que dispõe sobre a implementação do Plano de Metas Compromisso Todos pela Educação visando a articular o conjunto das ações do MEC e, ao mesmo tempo, disponibilizar para os estados, os municípios e o Distrito Federal instrumentos de avaliação e de implementação de políticas voltadas à melhoria da qualidade da educação (BRASIL, 2011b; BRASIL, 2007; BRASIL, 2007b).

De acordo com o MEC, o Plano de Metas Compromisso Todos pela Educação, pretende constituir um "novo regime de colaboração, que busca concertar a atuação dos entes federados sem lhes ferir a autonomia, envolvendo primordialmente a decisão política, a ação técnica e o atendimento da demanda educacional, visando à melhoria dos indicadores" (BRASIL, 2011a, p. 2). Os estados, os municípios e o Distrito Federal, ao aderirem ao Plano de Metas, são obrigados a elaborar o Plano de Ações Articuladas, que, na visão do governo, é um importante mecanismo de gestão, voltado para o planejamento de políticas educacionais em âmbito municipal e estadual, constituindo em instrumento de avaliação e controle capaz de promover a qualidade da Educação Básica (BRASIL, 2011b; BRASIL, 2007).

$\mathrm{Na}$ óptica do governo, inaugurou-se, portanto, um "novo regime de colaboração" entre os entes federados, que vem possibilitando, em tese, maior aporte de recursos técnicos e financeiros. O PAR se efetiva como termo de convênio ou de cooperação entre o MEC, os estados e os municípios para que possam estes receber recursos adicionais. O objetivo principal do governo federal é, por meio do PAR, garantir relativo padrão de planejamento aos processos de gestão dos sistemas públicos de educação, orientado pelos fundamentos do planejamento estratégico e, ao mesmo tempo, criar procedimentos de colaboração técnica e financeira entre os entes federados, como determina a Constituição $\mathrm{Federal}^{3}$ (BRASIL, 2000) e a Lei de Diretrizes e Bases da Educação Nacional (BRASIL, 2010).

Nesse contexto, um dos primeiros elementos a serem considerados, referente à efetivação do procedimento de fortalecimento do regime de colaboração, no caso específico, entre os municípios e a união, por meio do

\footnotetext{
3 A Constituição Federal (BRASIL, 2000), no Artigo 211, afirma que a União, os estados, o Distrito Federal e os municípios organizarão em "regime de colaboração" seus sistemas de ensino e a Lei de Diretrizes e Bases da Educação Nacional LDB (BRASIL, 2010). no artigo 8, reafirma que caberá à união, aos estados, ao distrito federal e aos municípios, em regime de colaboração, a organização dos sistemas de ensino.
} 
instrumento PAR, trata-se das reais condições dos sistemas municipais de educação de participarem do processo de elaboração dos componentes inerentes à estrutura formal do instrumento de planejamento do PAR e da formulação das regras conjuntas concernentes às obrigações e responsabilidades para se efetivarem os procedimentos de colaboração entre os entes federados.

Em relação à participação do processo de elaboração do instrumento de planejamento (PAR), os municípios não foram efetivamente consultados no que se refere a suas etapas constitutivas, às ações a serem realizadas e à divisão de tarefas entre os municípios e a união. Segundo Camini (2010), os movimentos iniciais que deram origem ao plano revelaram a participação de atores privilegiados em seu processo de elaboração, como a Unesco e o Unicef, por meio da presença de seus representantes em debates e na realização de pesquisas correspondentes à formulação das diretrizes do Plano de Metas Compromisso. A incorporação de outros sujeitos, como a Undime, a CNTE, o Consed, entre outros, com menor ou maior grau de participação, ocorreu como consequência de um plano previamente delineado. Assim, o que se observou no processo de elaboração do Plano de Metas Compromisso e do PAR é que a discussão não ocorreu de forma simultânea e coletiva: os sujeitos foram sendo chamados, consultados e incorporados no decorrer da formulação e execução da política. De maneira geral, verificou-se a elaboração de um plano sem ampla consulta às entidades científicas e sindicais do campo educacional e debate com elas. Os entes federados pronunciaram-se por meio de adesão ao Plano de Metas Compromisso, perdendo, de certa forma, a condição de protagonistas no processo.

Os depoimentos dos secretários municipais de educação revelam essa ausência de coesão entre os parâmetros do instrumento de planejamento e os anseios dos dirigentes municipais,

A gente espera recurso para as ações que pretendemos desenvolver, capacitações e interações entre as redes de ensino e essa integração e colaboração mais efetiva (...), não pode ser uma colaboração só do ponto de vista de quem está mandando fazer, a gente mais como órgão executor daquilo e daqui para lá vai muito pouco (...) só informação, a colaboração é muito mais neste sentido. Eles julgam, assim, vai fazer deste jeito que vai dar certo, mas vai ver o que o município está fazendo (..). As vezes nós estamos fazendo algo aqui que está dando certo, então tem que ser repensado (Secretario 6).

Porque tem as dimensões (...) são quatro dimensões e tem os indicadores. Tem que pontuar se é 1 ou 4. A dificuldade foi essa para saber qual era 1, qual era 4. E quando aquilo ali não dava certo para o nosso município, o que fazer? $\mathrm{O} 1$, às vezes, não tinha condição, não tinha nada a ver conosco, o 2 e 3 também não, às vezes $o$ 4 aproximava um pouquinho. Mas, não era bem aquilo ali que a gente precisava, então íamos para aquele que mais se aproximava da nossa realidade. E o que não fosse? E o que não fosse passaria, senão a gente não teria condição de terminar o 
PAR, de completar e iríamos perder coisas que às vezes a gente se interessava. Eu tinha que completar o PAR fazer parte dele porque se não ficaria fora do programa. Mas, ali nada adequava ao município, então, tinha que escolher um, senão as telas não passavam e era preciso completar o instrumento. Tinha que completar, não tinha jeito, não me dava opção, tinha que escolher um, servindo ou não você tem que escolher um (Secretario 8).

Os depoimentos esclarecem que as secretarias municipais de educação não foram devidamente consultadas sobre os parâmetros para a elaboração dos itens e das ações internas do PAR e, muito menos, para definir um projeto nacional articulado de planejamento educacional que envolvesse o conjunto dos municípios. Percebe-se que a forma em que esse paradigma colaborativo foi constituído mantém o município em uma condição de submissão às normas definidas pela união e corrobora a histórica visão restritiva do município como agente político capaz de induzir e formular políticas públicas (FONSECA; ALBUQUERQUE, 2012; FERREIRA; FONSECA, 2013).

As condições estruturais e organizacionais dos sistemas municipais de educação no que se refere a oferta do direito à educação também os coloca em uma situação de submissão e obediência às regras definidas pelos órgãos centrais. Os dados coletados por meio dos questionários revelam a precária estrutura das secretarias municipais de educação em Goiás no que concerne ao reduzido número de técnicos administrativos para a realização do trabalho pedagógico e burocrático. A pesquisa evidencia que, no universo de 12 municípios da amostra, sete deles possuem até três funcionários responsáveis pela parte administrativa e pedagógica nas secretarias. Evidentemente, essa deficiência na quantidade de profissionais interfere no desempenho das secretarias e compromete a realização dos trabalhos. Outro ponto a ser considerado é a quantidade de funcionários temporários. A pesquisa demonstra que metade dos técnicos atuantes nas secretarias é contratada e não consegue permanecer no cargo por longo período, condição que atrapalha o andamento dos serviços a serem prestados pela secretaria de educação devido à rotatividade dos funcionários.

Os dados demonstram também que a experiência técnica do secretário municipal de educação no exercício da função é relativamente pequena. Dos 12 secretários investigados que compõem a amostra, apenas quatro tiveram alguma experiência anterior na função e somente a metade deles, ou seja, seis secretários, fizeram algum curso de gestão pública antes de ocupar o cargo. Evidentemente, o curso de gestão não satisfaz plenamente todas as dúvidas administrativas concernentes ao exercício da função de secretário, mas, certamente, pode contribuir para ajudar o dirigente municipal a resolver determinados problemas 
burocráticos que podem surgir no cotidiano da administração pública. Na prática, a ausência de técnicos administrativos na quantidade suficiente e a rotatividade deles compromete a realização das etapas e o cumprimento das metas do plano.

Para a maioria dos secretários, o aspecto mais relevante do PAR foi a possibilidade de receber recursos financeiros federais adicionais para a aquisição de bens duráveis ou realizar obras de infraestrutura, compreensão que limita a disseminação no conjunto do sistema das outras dimensões do plano no campo pedagógico e administrativo. Assim, em razão das limitações estruturais, o plano perde parte efetiva de sua capacidade de intervenção no planejamento dos processos de gestão dos sistemas municipais a longo prazo.

Os depoimentos dos secretários mostram a carência dos recursos financeiros a serem destinados pelo PAR

Houve grande mudança no avanço das ações em nosso município, pois foram grandes conquistas recebidas desde ônibus até móveis e escola (CMEI) (Secretario 4).

Trazer obras para o município como uma quadra, porque nós não temos em nossa cidade. Então, era um sonho ter uma quadra, um lugar de esporte e lazer para [a\} gente trabalhar com os nossos alunos. Então, essa foi uma dimensão que nós escolhemos como prioritária (Secretario 5).

Então, de repente eu vou falar assim "não, o PAR nos ajudou na parte pedagógica". Mentira, porque nosso foco não foi esse. Nosso foco na parte pedagógica ficou por conta da prefeitura. Nosso foco foi a infraestrutura que nós não temos recursos para isso (Secretario 7).

Para completar o quadro, não há uma efetiva tradição de gestão democrática nos processos de decisão, situação que compromete a participação dos diversos agentes educacionais na definição dos parâmetros definidores de condução do plano. A pesquisa revela que, na maioria dos municípios, a secretaria municipal de educação é o principal agente definidor ou o centro efetivo de definição dos objetivos e metas a serem alcançadas no processo de elaboração do PAR, havendo relativa participação do conselho municipal de educação. Os demais agentes educacionais, como os professores e outros educadores não têm participação efetiva no processo. Com isso, pode-se concluir que há um significativo movimento de controle exercido pelos secretários concernente às principais decisões e, consequentemente, o enfraquecimento dos princípios democráticos.

Na grande maioria dos municípios, o Plano de Ações Articuladas foi elaborado em 2007 e, dentre todos, nove possuem o ComitêLocal de Compromisso. A existência do comitê é condição para a institucionalização dos procedimentos 
do PAR, mas os secretários assumem que têm dificuldades para conseguir reunir a comunidade para discutir os problemas educacionais e garantir o trabalho contínuo do comitê. Essa constatação sobre a dificuldade dos secretários em estabelecer práticas democráticas se reforça quando cruzada com a informação de que a maioria dos municípios não elaboraram o plano municipal de educação ou não o utilizam para a definição das políticas educacionais do município. Acrescenta-se a isso, a inexistência de procedimentos diretos de escolha coletiva para o cargo de diretor e coordenador pedagógico. Em relação ao provimento do cargo de diretor escolar, oito municípios mantêm a indicação política como procedimento para o exercício da função e, referente aos coordenadores pedagógicos, a maioria é indicada pelos diretores. Por meio desses dados, é possível aferir que, em razão das condições estruturais e da forte centralização política (SILVA, 2009), as secretarias têm dificuldades de instituir práticas efetivamente democráticas nos municípios.

Assim, os municípios sofrem com a ausência de uma estrutura organizacional adequada e de padrões democráticos no processo de tomada de decisões, situação que os coloca em posição de subordinação aos benefícios que a união pode conceder e, consequentemente, de sujeição no que se refere à construção dos parâmetros para a formulação coletiva do instrumento de planejamento. Esse contexto aumenta a responsabilidade da união de criar espaços públicos de discussão coletiva sobre os aspectos educacionais. Do ponto de vista cultural e político, essa tendência centralizadora existente nos municípios somente poderá ser equilibrada com o incentivo de práticas de diálogo e de construção coletiva, pois a inexistência de acordos e procedimentos democráticos pode conduzir à perda de legitimidade do padrão de gestão a ser instituído.

Essa situação de precarização e subordinação dos municípios resulta de uma histórica política de descentralização, potencializada pelos organismos internacionais, em sintonia com os interesses das elites nacionais, para os países em desenvolvimento, com o objetivo de transferir as responsabilidades públicas concernentes à educação para a dimensão do município e induzir alterações no campo da gestão, por meio de programas de estímulo à aplicação dos princípios da nova gestão pública. Essa prática, além de isolar os municípios no que se refere à satisfação econômica de suas necessidades educacionais básicas, também limitou os avanços no campo do desenvolvimento e aperfeiçoamento dos princípios da gestão democrática (CEPAL, 2005; SILVA, 2002).

Esse novo contexto educacional, constituído na década de 1990, conseguiu sustentar-se por intermédio de estratégias políticas diversas, dentre as quais a ressignificação de conceitos acadêmicos como o de descentralização, que representava a possibilidade de deslocamento do poder da esfera central do 
estado para a dimensão local, acompanhada dos recursos públicos necessários para a realização integral do trabalho educativo. Entretanto, o conceito de descentralização foi ressignificado, mantendo-se apenas a preocupação com a dimensão financeira (ARRETCHE, 1996; SHIROMA, 2000).

A efetivação do processo de descentralização que se tornou desconcentração das obrigações do poder público consolida-se como política pública com a formulação do Fundo de Manutenção e Desenvolvimento da Educação Básica e de Valorização dos Profissionais da Educação (Fundeb) ${ }^{4}$, fundo público criado com o objetivo de redistribuir os recursos captados nos estados e municípios, atribuindo à união a responsabilidade legal de complementar os fundos dos entes federativos que não alcançarem os valores mínimos (custo aluno/ano) definidos nacionalmente. Apesar dos esforços de complementação federal realizados durante os anos subsequentes à aprovação do fundo não conseguiu reverter a precariedade estrutural dos sistemas municipais de educação (PINTO, 2007).

$\mathrm{Na}$ prática, a ausência de discussões mais profundas referentes à consolidação do regime de colaboração ou à definição das responsabilidades financeiras das esferas governamentais no provimento da educação pública representa a limitação da autonomia dos municípios, bem como o fortalecimento da união como nível responsável pela regulação das políticas educacionais. Evidentemente, a constituição das políticas públicas educacionais, em especial as formuladas na década de 1990, traduzem uma consistente hegemonia política representada pelos interesses das corporações econômicas que vislumbram a ampliação de seus lucros na área em detrimento das instituições públicas que defendem a educação como direito social.

Nesse contexto, o papel regulador e avaliador do estado, somado aos elementos do mercado, buscaram um forte controle sobre as instituições educativas. A introdução do mercado no campo educacional passou a defender a competição, a liberdade de escolha e a descentralização para permitir, em tese, a chamada transparência da gestão, da eficiência e da qualidade das instituições de ensino, de forma pretensamente neutra, gerando a despolitização da discussão das complexas questões da educação. Verifica-se que a "ideologia política é substituída por uma política da racionalidade. As decisões deixam de ser políticas e colectivas para passarem a ser técnicas e individuais" (SEIXAS, 2001, p. 222).

4 Lei ñ. 11.494, de 20 de junho de 2007, que regulamenta o Fundo de Manutenção e Desenvolvimento da Educação Básica e de Valorização dos Profissionais da Educação (Fundeb) substitui a Lei nº. 9.424, de 24 de dezembro de 1996 que dispõe sobre o Fundo de Manutenção e Desenvolvimento do Ensino Fundamental e de Valorização do Magistério (BRASIL, 2017b). 
Assim, buscou-se construir uma ética social baseada nos valores da excelência e da competitividade em que a busca pela resolução dos problemas dos sistemas educativos passa necessariamente pela lógica do mercado e da gestão privada. Nesse contexto, no campo da educação, essas políticas se objetivaram por meio de múltiplas reformas estruturais de amplitudes diferentes, capazes de reduzir

A intervenção do estado na provisão e administração do serviço educativo, quer por meio de retóricas discursivas (dos políticos, dos peritos, dos meios de informação) de crítica ao serviço público estatal e de "encorajamento do mercado". Este "encorajamento do mercado" traduz-se, sobretudo, na subordinação das políticas de educação a uma lógica estritamente económica ("globalização"); na importação de valores (competição, concorrência, excelência etc.) e modelos de gestão empresarial, como referentes para a "modernização" do serviço público de educação; na promoção de medidas tendentes à sua privatização (BARROSO, 2005, p. 741).

Esse cenário revela os contornos que as políticas educacionais sofreram no decorrer das últimas décadas. A estrutura organizacional da educação brasileira passou a difundir a articulação entre os sistemas de ensino e a lógica produtiva. Desse modo, a diminuição de recursos públicos, a descentralização, a governação de caráter gerencial juntamente com o discurso da qualidade, da excelência, da competitividade, da meritocracia e do empreendedorismo traduzem a sobreposição da racionalidade privada sobre a dimensão pública. Assim, pode-se afirmar que, na medida em que se valoriza a educação com importante instrumento econômico, esvanece-se seu papel como propiciadora de igualdade social e cidadania.

A união fortalece essa perspectiva teórica referente ao papel do estado em suas atribuições de avaliador e regulador ao difundir para o campo da gestão dos sistemas públicos de educação o sentido de planejamento contido no paradigma da nova gestão pública. Nesse sentido, proliferam no campo da gestão educacional, sobretudo em relação às políticas públicas, os processos e o padrão administrativo empresarial, centrado na eficiência e na eficácia, para a cultura institucional dos sistemas educativos. Esse paradigma se sustenta pela valorização na estrutura do estado dos princípios técnicos utilizados pela iniciativa privada, dentre eles, a eficiência, a eficácia, o desempenho, a produtividade e o planejamento, que se tornam, cada vez mais, objetos centrais da gestão (FREITAS, SILVA, 2016).

Efetivamente, o impacto mais relevante trazido pelo PAR na alteração dos processos de gestão foi a instauração de práticas de maior controle sobre o trabalho do secretário municipal de educação. Como o instrumento de planejamento concentra as ações sob responsabilidade direta do secretário e o formato adotado pelos municípios para a realização das ações contidas no PAR 
foi de concentração de responsabilidades, percebe-se um aumento do controle do trabalho realizado pelo secretário de educação. Esse controle se manifesta na cobrança das ações fixadas pelos municípios diretamente no Sistema Integrado de Monitoramento, Execução e Controle do Ministério da Educação (SIMEC), no acompanhamento das obras realizadas no município, no acompanhamento das ações pertinentes ao PAR e na prestação de contas on line.

Os depoimentos dos secretários demonstram a intensificação dessas relações:

Eu acredito que sim! Porque querendo ou não, o MEC sabe o que o município pede, o que ele quer, o que ele precisa, o que ele recebe e, de certa forma, indiretamente, ele sabe, se vem tais recursos para educação ele tem que ser voltado para a educação, eu acredito que o MEC teve sim um certo controle em cima dos gestores (Secretário 11).

Prestação de contas, como é via online, você não pode mais atrasar, então você vai mais rápido. Então, por exemplo, a nossa reunião agora é justamente sobre uma prestação de conta que a gente quer fazer o mais rápido possível, a gente vai parar para fazer, então ela estimulou sim, você a estar sempre atualizado com a transparência, ela estimulou sim (Secretário 7).

O cumprimento dessas responsabilidades demanda significativa disposição de tempo e de recursos dos secretários que, na maioria dos casos, não possuem técnicos administrativos e pedagógicos capazes de auxiliá-los na realização desse trabalho. São os próprios secretários de educação que cuidam diretamente das responsabilidades, tanto do processo de acompanhamento das ações, como da prestação de contas no SIMEC, atribuições, que na maioria das vezes não são bem executadas em razão das limitações técnicas dos secretários, da ausência de infraestrutura nas secretarias e dos entraves pertinentes aos canais de comunicação criados pelo MEC para o esclarecimento de dúvidas sobre o PAR.

Em geral, os secretários estão bastante preocupados com os resultados alcançados pelos sistemas municipais de educação e pensam constantemente em estratégias pedagógicas capazes de alterar a performance dos alunos e os índices atingidos pelas escolas nos testes sistêmicos. Há uma percepção, entre os secretários, de que o parâmetro para se definir o nível e a qualidade de seu trabalho está diretamente relacionado aos índices educacionais alcançados pelo município.

Sim. É, após a análise dos resultados da Prova Brasil, passou-se a repensar tanto a prática avaliativa cotidiana quanto o currículo e as práticas pedagógicas (Secretário 9). 
De acordo com essas orientações, que sejam realizadas ações pedagógicas que tenha todos os conteúdos curriculares destinado a cada série com atividades elaboradas a nível da prova Brasil com o uso de recursos tecnológicos em sala de aula com diversos exercícios em sala de aula, com materiais concretos, nós utilizamos no decorrer do ano, uso de apostila específica de língua portuguesa, matemática, ciências utilizamos cadernos educacionais com atividades especificas em prol de estar fazendo este desenvolvimento. Essas orientações têm, sim, provocado alterações nos PPP das instituições propondo ações e metodologias a serem executadas de acordo com o ano letivo que propicie sempre um melhor desenvolvimento acadêmico aos nossos alunos (Secretário 11).

Então, melhorou a situação. Esses resultados da Prova Brasil e do IDEB estão sendo utilizados para redefinir as políticas educacionais do município? Sim, agora mesmo a gente já vai estar pensando para fazer o Plano Municipal, sobre esta questão (Secretário 2).

Os dados da pesquisa demonstram relativa interferência dos dispositivos contidos no instrumento de planejamento PAR na gestão dos sistemas municipais. Todavia, o grau de interferência sobre a gestão se restringe à percepção dos secretários da necessidade de intensificar as práticas de diagnóstico da situação educacional do município, de aumentar os esforços para garantir o cumprimento das ações acordadas no Termo de Compromisso do PAR, de elaborar estratégias pedagógicas capazes de melhorar os índices educacionais dos municípios nos testes sistêmicos, de aumentar o controle sobre o trabalho realizado pelo secretário de educação e de assegurar um processo efetivo de prestação de contas on line.

Apesar da relativa interferência desses dispositivos nos processos de gestão dos sistemas, a pesquisa revela as limitações do MEC no cumprimento de suas responsabilidades no que concerne ao acompanhamento, controle e avaliação durante o processo de implementação do PAR.

Eles ligavam (...) "olha você não preencheu" e a cobrança era interessante. Para ver se a coisa estava funcionando! Parou de existir, então, eu acho que é uma coisa interessante este diálogo entre as esferas. Como está? Está saindo ou não? Está acontecendo ou não? No início, no primeiro PAR, isso era constante, a cobrança era maior e depois, isso foi deixado de lado. Hoje em dia a cobrança é mais do acompanhamento da execução com relação \às obras (...) as coisas que se compra (...), as ações pedagógicas mesmo (...) as outras ações elas deixaram de ter esse acompanhamento e essa cobrança com relação aos próprios técnicos (Secretário 6).

Então as dificuldades para se alcançar as metas do PAR foram em razão do que? Dessa falta mesmo de falar mais sobre o PAR, vendo em que realmente ele é importante (...), mas perdeu as forças não teve mais esse segmento daquilo que está ali (...) as metas descritas. Então vamos alcançar (...) Tanto nós alcançamos (...) o primeiro teve monitoramento, mas esse agora não fez monitoramento, não foi aberto a via para fazer. Para gente saber direitinho. Esse monitoramento é feito pelo MEC? Não. Quem faz é aqui mesmo. O monitoramento é feito pela secretaria. 
Esse último (...) porque ele é feito de dois em dois anos pelo MEC (...) ainda não teve (...) não sei se mudou o sistema (...) o que é! O outro a gente fez e ai via o que fez e o que não fez para fechar e esse, até agora não teve, não. É o segundo PAR do município? É (Secretário 2).

Tínhamos no primeiro momento uma avaliação dentro do PAR. Agora, ficou meio que esquecido! Precisamos repensar! Eu estava olhando e perguntando, quanto cumprimos de cada ação aqui? Então já passou da hora de fazermos. Então, já foi mais sistematizado. Hoje, não! (Secretário 6).

A ausência de acompanhamento técnico e financeiro do MEC revela que o governo federal não cumpre integralmente suas responsabilidades definidas no plano, que pretendia estabelecer um regime de colaboração entre a união e os municípios. Em geral, as secretarias municipais de educação não têm estrutura física, quadro de funcionários e organização logística adequada para realizar plenamente as determinações contidas nesse instrumento de planejamento. Assim, percebe-se que a condição determinante para os municípios continuarem a desenvolver as ações e cumprirem as metas do plano é o apoio contínuo e incondicional da união para o alcance das responsabilidades definidas no Termo de Compromisso.

O PAR materializa muito mais a tentativa do MEC de consolidar os parâmetros do processo de descentralização e transferir para os sistemas municipais de educação os fundamentos da nova gestão pública do que a disposição da união de instituir práticas mais colaborativas entre os entes federados por meio do instrumento. $\mathrm{Na}$ realidade, a formulação de um instrumento de planejamento que se disponha a fortalecer as relações de colaboração, depende da constituição de um amplo consenso entre os entes federados em torno de um projeto nacional articulado de educação sustentado pela união, pois se trata da esfera governamental com mais recursos públicos e que agrega a estrutura técnica adequada para arcar com o desafio de construir esse projeto articulado com as demais instâncias (PINTO, 2007). Efetivamente, não seria possível constituir relações de maior colaboração entre os entes sem a definição de um acordo econômico referente às responsabilidades da união no financiamento e no apoio técnico aos municípios.

As pesquisas revelam que, em razão dos benefícios financeiros contidos no PAR, como a possibilidade de construir mais prédios escolares e equipar os sistemas educativos, muitos municípios aderiram ao plano e realizaram suas etapas constitutivas, mesmo sem as condições mínimas para a execução plena dos dispositivos do plano. Isso demonstra que o PAR materializa um paradigma restritivo de planejamento educacional, pois sustenta a tese de que a técnica por si possui legitimidade suficiente e conseguirá impor-se independente do consenso político e das condições financeiras adequadas. Essa característica tem respaldo na 
história do planejamento no Brasil, em que diversos planos foram definidos pela tecnocracia estatal sem a consulta ou a definição de acordos com as demais esferas governamentais e as organizações da sociedade civil. Essa tradição contém a ideia de que a união define os critérios e as normas e os estados e municípios obedecem as regras estabelecidas em troca de recursos financeiros adicionais (FONSECA; ALBUQUERQUE, 2012; FERREIRA; FONSECA, 2013; CAMINI, 2009; FERREIRA, 2012; FREITAS; SILVA, 2016; CASTRO; CHAVES; SILVA, 2016).

O MEC, no governo Lula da Silva (2003-2010) ao definir os pressupostos do PDE e do PAR, com a intenção de constituir o suposto regime de colaboração, reproduziu esse mesmo sentido conservador ao consultar, principalmente, o grupo de empresários reunidos no movimento Compromisso Todos pela Educação para formular o projeto, ou seja, sustentou a teoria de que o projeto educativo desse grupo seria suficiente para abarcar o restante dos segmentos sociais e realizar as mudanças necessárias à educação. Na prática, esse projeto encontra diversas barreiras para se concretizar, pois um efetivo regime de colaboração com a definição das respectivas responsabilidades administrativas e financeiras não se sustenta, do ponto de vista político, sem ampla aliança e um projeto educativo exaustivamente discutido e debatido pelos diversos grupos sociais.

\section{CONSIDERAÇÕES FINAIS}

Evidentemente, todo processo de planejamento educacional contém a tentativa política de consolidar uma visão de sociedade sustentada por determinados grupos econômicos. O PAR, ao priorizar a racionalidade técnica como elemento articulador do projeto educativo, não consegue operacionalizar seus objetivos a contento, porque não possui as condições estruturais e políticas para se efetivar. Essa situação expõe a ausência de um amplo e consistente acordo político na sociedade brasileira, referente à perspectiva de educação, de sociedade e de planejamento que deve sustentar a organização do sistema educacional brasileiro. Os avanços constitucionais contidos na $\mathrm{EC} \mathrm{n}^{\circ} 59$, referente à articulação de um sistema nacional de educação em regime de colaboração, tendem a não se efetivar em razão dos fortes interesses econômicos das corporações educacionais e grupos empresariais que defendem a concepção de educação como serviço (BRASIL, 2017c).

O predomínio dos acordos econômicos e políticos com as grandes corporações educacionais e os setores empresariais durante o governo Lula da Silva (2003-2010) e Dilma Rousseff (2011-2016), em detrimento de maior aliança com os movimentos sociais e os defensores da educação pública, impediram maiores avanços referentes às responsabilidades financeiras e técnicas dos entes 
federados, em especial da união, na efetivação do sistema nacional articulado de educação. O papel regulador e avaliador do estado, submetido a uma perspectiva de neoliberalismo de terceira via, foi demasiadamente absorvido como projeto político por esses dois governos e, por esse motivo, não houve a abertura de discussões mais consistentes concernentes ao papel do estado e de seus níveis de intervenção econômica no provimento da educação pública e gratuita para todos.

A proliferação dos debates referentes a uma melhor distribuição das responsabilidades e à formalização de um efetivo regime de colaboração em que a união assuma o protagonismo no processo de financiamento da educação nacional não interessa aos objetivos competitivos das corporações educacionais, que apostam na competição, na meritocracia e na concepção de educação como serviço. Assim, recuperar as contradições e os limites de operacionalização do PAR como instrumento de planejamento capaz de consolidar práticas colaborativas entre os entes federados nos remete aos limites da atual perspectiva educacional e, principalmente, nos conduz a retomarmos as discussões concernentes à definição de uma ampla aliança no tocante a um projeto educativo mais abrangente e, principalmente, capaz de definir com maior precisão o papel interventor do estado como instituição capaz de garantir a educação pública e gratuita como direito de todos.

\section{REFERÊNCIAS}

ARRETCHE, Marta. Mitos da Descentralização: Maior Democracia e eficiência nas Políticas Públicas?. Revista Brasileira de Ciências Sociais, São Paulo, v. 11, n.31, p. 44-66, 1996.

BARROSO, João. O estado, a educação e a regulação das políticas públicas. Educação e Sociedade. Campinas, vol. 26, n. 92, p. 725-751, Especial, out. 2005.

BORDIGNON, Genuíno. Gestão da educação no município: sistema, conselho e plano. São Paulo: Editora e Livraria Instituto Paulo Freire, 2009.

BRASIL. IBGE. Instituto Brasileiro de Geografia e Estatística. Disponível em http://www.ibge.gov.br/home/ Acesso em: 17 fev. 2017a.

BRASIL. Lei no $\mathbf{1 1 . 4 9 4}$, de 20 de junho de 2007, que regulamenta o Fundo de Manutenção e Desenvolvimento da Educação Básica e de Valorização dos Profissionais da Educação (Fundeb). Disponível http:www.planalto.gov.br/ ccivil_03/_ato2007-2010/2007/lei/111494.htm Acesso em 2017b. 
BRASIL. Emenda Constitucional nº 59, de 11 de novembro de 2009. Disponível http://www.planalto.gov.br/ccivil_03/constituicao/emendas/emc/ emc59.htm Acesso em 2017c.

MEC. Plano de Ações Articuladas (PAR) 2011-2014: guia prático de ações. Novembro, 2011a.

Orientações para elaboração do plano de ações articuladas (PAR) dos municípios (2011-2014). Versão Preliminar. Setembro, 2011 b.

LDB. Lei de Diretrizes e Bases da Educação Nacional, $5^{\circ}$ ed., Brasília: Imprensa Nacional 2010.

Plano de Desenvolvimento da Educação: razões, princípios e programas. Brasília: MEC, 2007.

Decreto $\mathbf{n}^{\circ}$ 6.094, de 24 de Abril de 2007. Dispõe sobre a implementação do Plano Plano de Metas Compromisso Todos pela Educação, pela união federal, em regime de colaboração com municípios, distrito federal e estados, e a participação das famílias e da comunidade, mediante programas e ações de assistência técnica e financeira, visando a mobilização social pela melhoria da qualidade da educação básica. Brasília: Imprensa Nacional, 2007b.

BRASIL. Constituição da República Federativa do Brasil de 1988. Brasília: Senado Federal, Subsecretaria de Edições Técnicas, 2000.

CAMINI, Lúcia. A política educacional do PDE e do Plano de Metas Compromisso Todos pela Educação. RBPAE - v. 26, n. 3, set./dez., p. 535-550. 2010

A gestão educacional e a relação entre entes federados na política educacional do PDE/Plano de Metas Compromisso Todos pela Educação, 2009, 298 f. Tese (doutorado em Educação) - Universidade Federal do Rio Grande, Rio Grande, 2009.

CASTRO, Alda Maria Duarte Araújo; CHAVES, Vera Lúcia Jacob; SILVA, Marcelo Soares Pereira (organizadores). In Plano de ações articuladas: propostas, cenários e desafios. Campinas, SP: Mercado de Letras, 2016. 
CEPAL. Invertir mejor, para invertir más: financiamento y gestión de la educación em América Latina y Caribe. Santiago, Chile: CEPAL/UNESCO, 2005.

FERREIRA, Eliza B. Planejamento educacional e tecnocracia nas políticas educacionais contemporâneas. Série Estudos - Periódico do Programa de PósGraduação em Educação da UCDB - Campo Grande, no 34, p. 45-59, jul./dez. 2012.

FERREIRA, Eliza B.; FONSECA, Marília (orgs.). Política e planejamento educacional no Brasil do século 21. Brasília: Liber Livro, 2013.

FONSECA, Marília; ALBUQUERQUE, Severino V. O PAR como indutor do planejamento da educação municipal. Série Estudos - Periódico do Programa de Pós-Graduação em Educação da UCDB - Campo Grande, no 34, jul./dez., p. 61-74. 2012.

FREITAS, Cecília Carolina Simeão; SILVA, Marcelo Soares Pereira. O Plano de Desenvolvimento da Educação no contexto do novo desenvolvimentismo brasileiro. RBPAE, v. 32, n. 1, jan./abr, p. 69-88, 2016.

PINTO, José Marcelino de Rezende. A política recente de fundos para o financiamento da educação e seus efeitos no pacto federativo. Educ. Soc. [online], vol.28, n.100, p. 877-897, 2007;

ROMÃO, José E. Sistemas municipais de educação: a lei de diretrizes e bases e a educação no município. São Paulo: Editora e Livraria Instituto Paulo Freire, 2010.

SEIXAS, Ana Maria. Políticas educativas para o ensino superior: a globalização neoliberal e a emergência de novas formas de regulação social. In: STOER, Stephen R., CORTESÃO, Luiza; CORREIA, José A. (orgs.). Transnacionalização da educação: da crise da "educação" à educação da crise. Porto: Afrontamento, 2001.

SILVA, Luís Gustavo A. Os processos de dominação na escola pública. Goiânia: Editora PUC-GO, 2009.

SILVA, Maria Abadia. Intervenção e consentimento: a política educacional do Banco Mundial. Campinas: Autores Associados; São Paulo: Fapesp, 2002. 
SHIROMA, Eneida Oto, MORAES, Maria Célia Marcondes, EVANGELISTA, Olinda (orgs.) Política Educacional. Rio de Janeiro: DP\&A, 2000.

LUÍS GUSTAVO ALEXANDRE DA SILVA é doutor em Educação pela Universidade Federal de Goiás (UFG) - 2009. Professor Adjunto da Faculdade de Educação da Universidade Federal de Goiás e vice coordenador do Núcleo de Estudos e Documentação: Educação, Sociedade e Cultura - Nedesc. Atualmente, é coordenador do Projeto de Pesquisa Organização e Gestão dos Sistemas Municipais de Educação com financiamento do CNPq - Chamada Universal 14/2013 - Faixa A. Tem experiência na área de Educação, com ênfase em Políticas Educacionais, atuando principalmente nos seguintes temas: Gestão Educacional, Gestão de Sistemas Educativos e Gestão Escolar. E-mail: luisgas1@gmail.com

Recebido em janeiro de 2017 Aprovado em abril de 2017 